\title{
MR Thermometry in Cerebrovascular Disease: Physiologic Basis, Hemodynamic Dependence, and a New Frontier in Stroke Imaging
}

\author{
(D) S. Dehkharghani and (DD. Qiu
}

\begin{abstract}
SUMMARY: The remarkable temperature sensitivity of the brain is widely recognized and has been studied for its role in the potentiation of ischemic and other neurologic injuries. Pyrexia frequently complicates large-vessel acute ischemic stroke and develops commonly in critically ill neurologic patients; the profound sensitivity of the brain even to minor intraischemic temperature changes, together with the discovery of brain-to-systemic as well as intracerebral temperature gradients, has thus compelled the exploration of cerebral thermoregulation and uncovered its immutable dependence on cerebral blood flow. A lack of pragmatic and noninvasive tools for spatially and temporally resolved brain thermometry has historically restricted empiric study of cerebral temperature homeostasis; however, MR thermometry (MRT) leveraging temperature-sensitive nuclear magnetic resonance phenomena is well-suited to bridging this long-standing gap. This review aims to introduce the reader to the following: 1) fundamental aspects of cerebral thermoregulation, 2) the physical basis of noninvasive MRT, and 3) the physiologic interdependence of cerebral temperature, perfusion, metabolism, and viability.
\end{abstract}

ABBREVIATIONS: $\mathrm{BOLD}$ = blood oxygen level-dependent; $\mathrm{BTR}=$ brain thermal response; NMR = nuclear magnetic resonance; OEF = oxygen extraction fraction; PRESS = point-resolved spectroscopy; PRF = proton resonance frequency

C erebral thermoregulation is a critical, but enigmatic aspect of brain physiology at the intersection of cerebral perfusion and metabolism. The brain exhibits exquisite sensitivity to disruptions in temperature homeostasis, with even small elevations rapidly potentiating ischemic or other neurologic injuries. ${ }^{1-5}$ Nevertheless, formalized and experimentally tested theories of cerebral temperature control are lacking, due to the absence of pragmatic tools to measure spatiotemporally-resolved thermal gradients under physiologic and pathologic conditions. This review aims to introduce the reader to fundamental principles of cerebral temperature (dys)regulation and homeothermy, with an emphasis on temperature as a potential biomarker of

Received November 13, 2019; accepted after revision January 2, 2020.

From the Department of Radiology (S.D.), New York University Langone Health, New York, New York; and Department of Radiology (D.Q.), Emory University Hospital, Atlanta, Georgia.

Portions of this work were supported by the American Society of Neuroradiology Scholar Award in Neuroradiology Research (2012-2013, 2013-2014), and an Emory University Research Committee (2013-2014) grant awarded to the lead author. This work was supported, in part, by National Center for Research Resources and the Office of Research Infrastructure Programs of the National Institutes of Health (P51RR000165, OD P51OD011132).

Please address correspondence to Seena Dehkharghani, MD, Center for Biomedical Imaging, Department of Radiology, New York University Langone Medical Center, 660 First Ave, 2nd Floor, Attention Hillary Gumiel, New York, NY 10016; e-mail: Seena.Dehkharghani@NYUMC.Org

- Indicates open access to non-subscribers at www.ajnr.org

http://dx.doi.org/10.3174/ajnr.A6455 cerebrovascular disease and the use of noninvasive approaches to measuring brain temperatures using MR thermometry.

\section{THERMOREGULATION AND TEMPERATURE HOMEOSTASIS}

Body temperature is tightly controlled in humans at approximately $37^{\circ} \mathrm{C}$ and regulated through the balance of heat-conserving and heat-dissipating mechanisms mediated by the hypothalamus. ${ }^{6}$ Most heat production arises from so-called obligatory thermogenesis-that is, the thermal energy of metabolically active organs, including the brain, with the remainder arising from voluntary and involuntary muscle activity or acquired passively from ambient sources. ${ }^{6}$ While the body efficiently dissipates heat primarily through radiative as well as conductive, convective, and evaporative mechanisms, cerebral thermoregulation proves more complex. Throughout much of the highly metabolic brain (consuming $20 \%$ of the oxygen and $25 \%$ of the glucose at only $2 \%-3 \%$ of the total body weight), ${ }^{7}$ the temperature exceeds that of the arterial inflow. While superficial cortical brain regions may dissipate heat to a greater extent through convention/conduction and radiation, cerebral temperature homeostasis largely depends on steady CBF to sustain countercurrent heat exchange mechanisms that prevent cerebral hyperthermia and prove critical to normal brain physiology. ${ }^{6,8-10}$ The specific influence of systemic temperatures on cerebral thermoregulation, however, remains 
poorly understood. Existing studies have produced discrepant and sometimes contradictory conclusions regarding: 1) the direction and magnitude of the brain-to-systemic temperature offset in certain brain regions, 2) the spatial distribution and magnitude of intracerebral temperature gradients, and 3) the specific mechanisms by which potentially mild pyrexia potentiates myriad forms of neurologic injury, including ischemia.

The implications of cerebral thermosensitivity, in fact, reach beyond a manifest susceptibility to injury and may even have steered the course of human evolution. Specifically, the development of efficient mechanisms of heat dissipation are proposed to have released human ancestors from fundamental thermal constraints to brain development and growth. Simply, the energetic cost and therefore the metabolic output of the large human brain poses considerable demands on such mechanisms of temperature control, the development of which facilitated the remarkable encephalization of early humans. ${ }^{11-13}$ Thus, by comparison with other key constraints of human evolution, brain temperature was emphasized by Baker (1979) ${ }^{13}$ to be the "single most important factor limiting the survival of man and other animals." Neuroprotective adaptations such as selective brain cooling-the maintenance of brain temperatures selectively despite rising peripheral temperatures by rerouting cooler, valveless facial/ocular and emissary venous supply-were therefore critical for thriving humans under thermal stress, exercise, and so forth. ${ }^{8,13-15}$ Such adaptations are traceable to recognized changes in the human calvarial fossil record, developing in tandem with epochs of immense advancement, and may have compensated for the loss in humans of the rete caroticum (ie, the rete mirabilis) first proposed by Herophilus 2000 years ago and documented later by Galen in other mammals including dogs, cats, and sheep. ${ }^{14,16-20}$ From these insights, a coherent picture of the evolving human brain emerged, linking intelligence, the growing brain, bipedalism, and efficient cerebral heat exchange in a seminal paradigm known as the radiator hypothesis, which aptly underscores the importance of steady blood flow at the nexus of temperature homeostasis. ${ }^{11-13,15,16}$ This point is easily contextualized when considering the thermogenicity of the metabolically active brain: Approximately $0.66 \mathrm{~J} / \mathrm{min} / \mathrm{g}$ are produced by the brain, primarily by the consumption of oxygen through chemical reaction with glucose which, absent heat dissipation, would produce a rise of $0.16^{\circ} \mathrm{C} / \mathrm{min}^{18,21,22}$

The study of cerebral thermoregulation, nevertheless, remains difficult. Past investigations have consisted mostly of surrogate measures of brain temperature (eg, tympanic, sublingual, and etc.) and sporadic human and animal studies using directly implanted temperature probes. Surrogate measures, however, are limited by the presence of temporally varying offsets relative to actual brain temperatures. ${ }^{23-26}$ Implantable probes are similarly suboptimal for large-scale experimentation due to their requisite invasiveness and cost, ${ }^{27-30}$ which limit their widespread placement throughout the brain and in turn, their suitability for interrogation of spatially distributed temperature gradients. ${ }^{27,29,31,32}$ Notwithstanding their limitations, a small number of animal and human studies have confirmed the presence of measurable spatial temperature gradients that can be altered during brain injury. 2,9,21,29,33-41 A theoretic framework for understanding temperature homeostasis has also been established through numeric simulations often based in the seminal bioheat equations proposed by Pennes (1948), ${ }^{42}$ and the reader is referred to excellent resources on the topic. ${ }^{8-10,43-47}$

\section{CENTRAL FEVER AND CEREBRAL TEMPERATURE DYSREGULATION DURING HYPOPERFUSION}

Systemic and cerebral temperature dysregulation during and following neurovascular ischemia is well-described, yet the mechanisms underpinning this relationship remain unclear.

The sensitivity of neuronal substrate to hyperthermia has been the focus of multiple human and animal stroke studies, and identification of this potentially modifiable biomarker has naturally promoted investigation into therapeutic cooling protocols following different forms of neurologic injury. ${ }^{1,2,4-6,48}$ Indeed, therapeutic cooling remains among the most potent neuroprotectants following ischemia and cardiac arrest, dating to landmark studies of the mid-20th century. ${ }^{49,50}$ Early canine studies by Hosler $(1953)^{49}$ found that at a body temperature of $20^{\circ} \mathrm{C}$, no neurologic injury was observed following resuscitation from 1113 minutes of cardiac fibrillation. Similarly, Donnelly $(1956)^{51}$ reported that brain anoxia can be tolerated for only 3 minutes at physiologic temperatures, but remarkably with full resistance for 9 minutes when cooling to $26.5^{\circ} \mathrm{C}$. In part through depression of metabolic demand-a 2.2-fold reduction in oxygen consumption for each $10^{\circ} \mathrm{C}$ decrease in temperature-as well as protection against immediate and programmed cytotoxicity and vascular permeability, brisk hypothermia $\left(\sim 20^{\circ}-32^{\circ} \mathrm{C}\right)$ permits prolonged circulatory arrest potentially with little neurologic injury. ${ }^{7}$ Decades of subsequent investigation have highlighted the protective attributes of corporeal and brain cooling following brain injury, yet a number of large-scale prospective trials have failed to capture a population-level benefit from cooling, owing perhaps to systemic adverse effects or, we posit, the use of non-neurologic temperature benchmarks. This latter point, we believe, holds tremendous potential promise for noninvasive brain thermometry, with which the known variability between systemic surrogates and brain temperatures can be disentangled toward more guided therapeutic hypothermia protocols.

In contradistinction, hyperthermia proves a strong potentiator of neurologic injury. ${ }^{1,2,5,52}$ Fever, an adaptation intended to raise host defenses, has been shown to influence clinical outcomes negatively following stroke, potentially even when mild. ${ }^{1,2,4-6,53-59}$ Fever following neurologic injury is unfortunately common, even without direct hypothalamic injury. ${ }^{60}$ While the mechanisms of central fever following ischemic stroke are incompletely understood, the aforementioned impairment in radiative heat exchange may act in concert with cytokine-mediated influences involving the hypothalamus, as well as more regional and zonal inflammatory trafficking as described by the inflammatory penumbra paradigm. ${ }^{6,7,41,53,61,62}$ These inflammatory cascades may be moderated through hypothermia which, together with reduced expression of pro-apoptotic genes, may provide a powerful potential target for intervention. ${ }^{63-66}$

Radiologic progression of ischemia due to hyperthermia remains comparatively less explored. We previously reported on the tendency for greater consumption of penumbral (ie, at risk) 
tissues in fully reperfused patients with acute ischemic stroke when fevers exceeded $37.5^{\circ} \mathrm{C}$ in the early stroke aftermath. While infarction expansion following reperfusion comprises an array of reported causes, identification of a potentially modifiable and readily attainable biomarker may significantly influence imaging and clinical outcomes. ${ }^{53,67}$

Larger studies, including a series of 4295 patients, have firmly established the detrimental effects of fever as producing longer intensive care unit and hospital stays, higher mortality, and overall worse outcomes, even when controlling for disease severity, complications, and age. ${ }^{68}$ We propose that the frequency with which pyrexia occurs in neurologically injured patients-up to $47 \%$ of neurologic patients in intensive care units (increasing to $93 \%$ after 2 weeks ${ }^{69}$ ) -itself motivates investigation into the use of noninvasive, direct brain thermography in diagnosis, prognostication, and perhaps treatment selection or response to therapy.

\section{MR THERMOMETRY}

\section{Principles and Techniques}

2D MRI thermometry dates to initial experimentation by Parker et al, ${ }^{70}$ who studied the temperature sensitivity of proton longitudinal relaxation (T1) times in human blood specimens, decades after the far earlier discovery of temperature-sensitive nuclear magnetic resonance (NMR) phenomena in the mid-20th century. While a strong linear relationship and sensitivity of $\sim 2^{\circ} \mathrm{C}$ was reported from a 5-minute scan, the speed and accuracy of T1 thermometry have limited its application in neuroscience. Subsequently, other temperature-sensitive MRI contrast mechanisms were explored, including transverse relaxation time (T2), equilibrium magnetization/susceptibility, spin density, microscopic diffusion, and the proton resonance frequency (PRF), the latter now most commonly used, particularly for thermal ablative procedures (eg, laser interstitial thermal therapy, high-intensity focused ultrasound, and radiofrequency ablation). ${ }^{71}$ While each approach may offer relative, application-specific advantages, PRF thermometry, which exploits either of 2 attributes of the proton resonance frequency, is the most accurate, versatile, and widely used technique and will be the subject of the remainder of this review. ${ }^{72}$ Specifically, this review will emphasize clinically pragmatic approaches allowing the sufficient spatial, temporal, and temperature resolution to probe dynamic thermal gradients in the healthy brain and during cerebrovascular impairment. Emerging strategies, including potentially promising and accurate temperature-sensitive contrast agents, remain unfit for translational human or clinical imaging and are beyond the intended scope of this review; however, the interested reader is referred to thorough topical reviews on the subject. ${ }^{73-75}$

\section{PRF Thermometry}

PRF thermometry stems from the temperature dependence of the water proton chemical shift. Due to the shielding effects of their surrounding electron currents, the magnetic field experienced by hydrogen protons varies slightly relative to that of the externally applied field $\left(\mathrm{B}_{0}\right)$. The effect manifests in a temperature-dependent chemical shift $(s)$ as follows:

$$
\omega(T)=\gamma \cdot[1-s(T)] \times B_{\text {local }}
$$

where $\omega(T)$ represents the angular frequency of proton precession; $\gamma$, the gyromagnetic ratio $(\sim 42 \mathrm{MHz} / \mathrm{T}$ for the hydrogen nucleus); and $s(T)$, the temperature-dependent chemical shift modulated by the electron-shielding effect on the local magnetic field $\left(B_{\text {local }}\right)$, itself a function of both the externally applied $\left(\mathrm{B}_{0}\right)$ field and spatially varying magnetic susceptibility. The shielding effect of the water proton is influenced heavily by the strength of hydrogen bonds, which is a function of temperature. Hydrogen bonds are formed between the hydrogen of 1 water molecule and the electronegative oxygen atom of another water molecule (Fig 1A). Hydrogen bonds among water molecules, therefore, reduce the opposing electron currents about the bound hydrogen proton, exposing the proton to less attenuated $B_{\text {local }}$ fields, thereby inducing higher precessional frequencies. (Fig 1B). At higher temperatures, however, the hydrogen bonds between water molecules become less stable and/or disrupted, resulting in greater electronic shielding and therefore reduced magnetic flux density and a lower frequency of precession of the hydrogen proton. It has been shown in multiple studies, including our own, that the water proton chemical shift $s(T)$ is largely a linear function of temperature $T$, (Fig $1 C$ ):

$$
s(T) \approx s_{0}+\beta \times(T-37)
$$

where $S_{0}$ denotes the chemical shift at $37^{\circ} \mathrm{C}$ and $\beta$ denotes change in chemical shift per unit increase in temperature. $\beta$ has been measured to be between -0.009 and -0.011 ppm per degree Celsius, ${ }^{29,72,76,77}$ dating to its initial description in NMR by Hindman (1966). ${ }^{77}$

While most MR thermometry applications have sought to measure relative temperature changes (eg, during and following thermal ablation), they are poorly suited for the study of baseline temperatures and pathophysiologic temperature gradients between brain regions, comparisons between subjects, or longitudinal study, together motivating the development of quantitative techniques approximating absolute temperatures. As apparent from Equation 1, an accurate measure of the chemical shift difference would require precise measurement of $B_{\text {local }}$ down to $0.01 \mathrm{ppm}$. To resolve this issue, a stable (ie, non-temperature-dependent) reference frequency is necessary to normalize the water frequency, thereby allowing nearly absolute thermometry based on the temperature-dependent chemical shift difference between the 2 (or sometimes more) metabolites. Such self-referenced thermometry has been the subject of considerable study using the chemical shift difference between the temperature-sensitive water resonance and a non-temperaturesensitive reference metabolite, such as the methyl resonance of neuronal NAA at $\sim 1.98 \mathrm{ppm}$.

By comparison, when the primary interest is simply the collection of relative changes in temperature across time, for example during ablative procedures, explicit measurement of either water or reference metabolite frequency is unnecessary, and a baseline water resonance phase can instead be measured before treatment begins. Thereafter, a relative temperature 

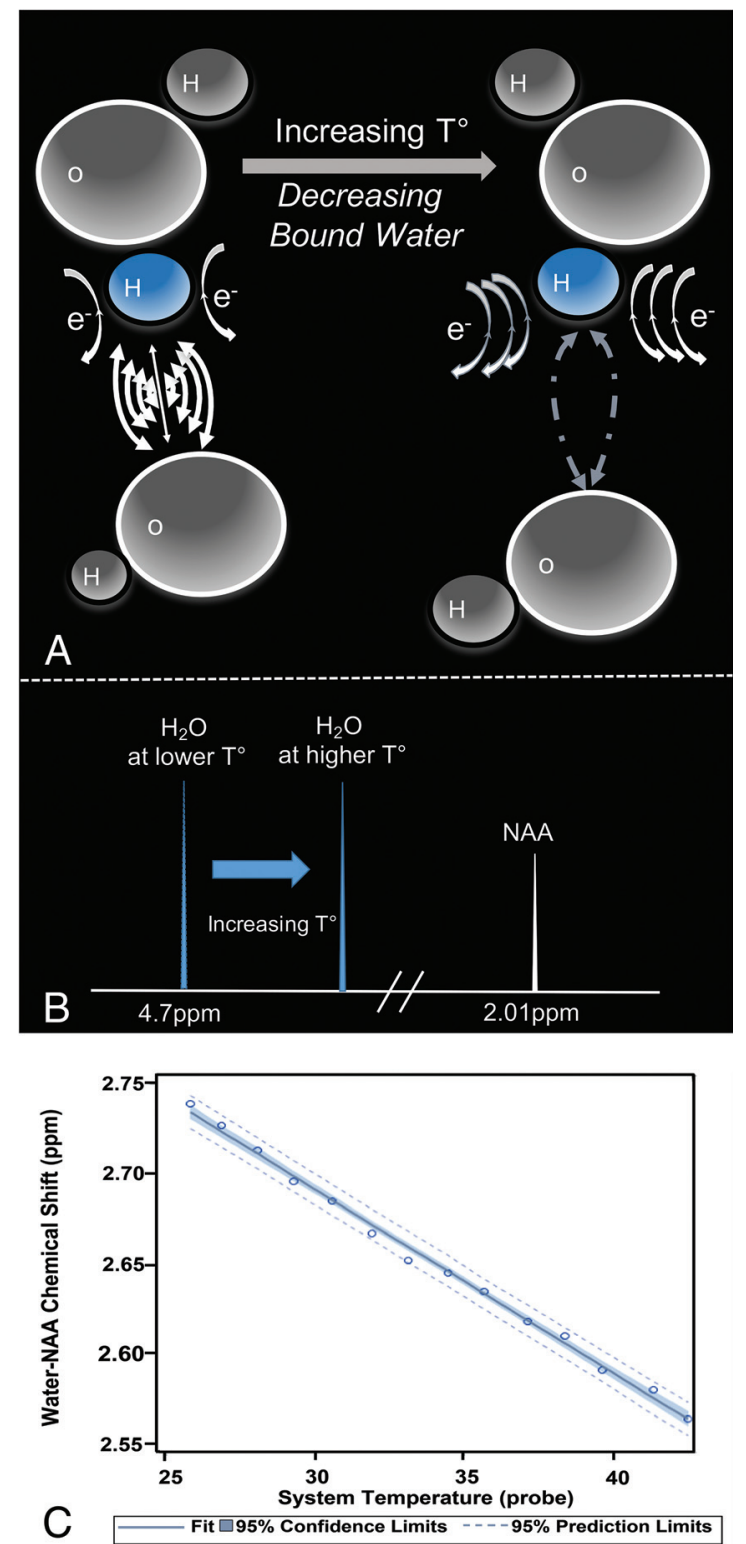

FIG 1. A, Schematic representation of the temperature-dependency of the water proton resonance frequency chemical shift. A water hydrogen bonding scenario for water molecules in two milieu of differing temperatures is depicted. Increasing temperatures drive the water hydrogen bonding equilibrium towards greater free water proportions through disruption of hydrogen bonds. Electronic currents ("e-") about the hydrogen proton shield it from the main magnetic flux, but will vary in strength between strongly (left) and weakly (right) bound water pools. The greater shielding of free water hydrogens (right) yields lower precessional frequencies, governed by the gyromagnetic ratio of hydrogen, $\sim 42 \mathrm{MHz} / \mathrm{T}$. B, Within the hydrogen PRF spectrum, higher temperatures translate the water resonance upfield (i.e. towards lower chemical shifts), reducing the chemical shift difference between water and a non-temperature dependent reference such as the methyl resonance of NAA, producing a linear correlation coefficient $(C)$ of $\sim-0.01 \mathrm{ppm} / \mathrm{C}$. As shown, the relationship between hydrogen bonding equilibrium, PRF, and temperature remains linear across even supraphysiologic temperature ranges as demonstrated in an aqueous cytosolic phantom during real time fiberoptic temperature monitoring. Adapted from Dehkharghani et al. ${ }^{76}$ change can be estimated following ablation using an additional phase estimation, and the phase shift can be used to estimate a relative temperature change on the basis of the aforementioned temperature-dependent frequency changes. In this case, the phase evolution arising from the PRF change relates to the relative temperature change as follows:

$$
\begin{aligned}
\Delta \varphi_{t} & =-2 \pi \cdot \Delta \omega_{t} \times T E \\
& =-2 \pi \times\left(\omega\left(T_{1}\right)-\omega\left(T_{0}\right)\right) \times T E \\
& =2 \pi \times \gamma \times \beta_{w} \times B_{\text {local }} \times T E \times \Delta T,
\end{aligned}
$$

where $\beta_{w}$ reflects the thermal chemical shift coefficient of water. Importantly, however, non-temperature-dependent changes in phase, including, for instance, those due to magnetic field drifts across time resulting from gradient heating or subject motion can engender errors in the imputed temperature change. In either case, phase imaging can be used only to estimate relative temperature changes across time, though with comparatively higher spatial and temporal resolution than most quantitative thermometry techniques. ${ }^{71}$ In principle, any sequence that is sensitive to PRF can be used to measure the phase change across time, and the most common approach is through phase imaging from a gradient-echo sequence, according to the equation $\Delta \varphi_{t}=-2 \pi \times \Delta \omega_{t} \times T E$, where $\Delta \varphi_{t}$ represents the phase change across time, and TE, the echo time. More recently, "reference-less" phase thermometry methods have been proposed, which assume temperature changes occurring only in a local region and essentially using the phase from the neighboring regions as an in-line reference, though their robustness and accuracy as alternatives to truly self-referenced techniques have not been conclusively demonstrated. ${ }^{78}$

As introduced above, using the chemical shift difference as measured from proton spectroscopy, absolute thermometry can be approached through the additional, simultaneous measurement of the PRF of another proton chemical group lacking in temperature-dependent hydrogen bonds. Provided that intravoxel susceptibility effects are small as shown by De Poorter, ${ }^{85}$ the use of a reference frequency devoid of temperature-dependent chemical shifts is thus performed as follows:

$$
\text { 4) } \begin{aligned}
\Delta \omega & =\Delta \omega_{w}-\Delta \omega_{r} \\
& =-\gamma \times\left(s_{0, w}-s_{0, r}+\left(\beta_{w}-\beta_{r}\right) \times(T-37)\right) \text {, }
\end{aligned}
$$

where, in contrast to Equation 3, $\Delta \omega$ denotes the difference in angular frequency between the water proton and the reference compound, such as NAA, choline, or other candidate hydrogen metabolites; $s_{0, w}$ and $s_{0, r}$ denote chemical shifts of water and the reference compound, respectively, at $37^{\circ} \mathrm{C}$; and $\beta_{w}$ and $\beta_{r}$ represent thermal chemical shift coefficients for water and the reference compound, respectively. ${ }^{79} \mathrm{NAA}$, the dominant nonwater metabolite in the conventional brain PRF spectrum, has proved generally well-suited due to its uniformly high concentration and extremely small temperature dependency $\left(<0.0007 \mathrm{ppm} /{ }^{\circ} \mathrm{C}\right)$ related to the absence of hydrogen bonds. Accordingly, MR spectroscopy can be used to measure the PRF difference between water and reference compounds simultaneously, facilitating 
quantitative temperatures at single time points or longitudinally, either between or among individual subjects and across experimental conditions. ${ }^{29,41,59,76,80}$

\section{MR Thermometry in Stroke and Cerebrovascular Disease}

Acute Ischemic Stroke. Noninvasive cerebral MRT has been explored in small-but-growing numbers of human and animal studies, aiming to capture empirically the link between brain temperature and hemodynamic compromise. While such mechanistic insights are valuable motivations for noninvasive MRT, the development of biomarkers of tissue viability and outcome arguably remain the most compelling long-term objective of thermometry in this setting.

Corbett et $\mathrm{al}^{29}$ first described the use of single-voxel proton MR spectroscopy for in vivo brain thermometry in a piglet model of ischemic stroke using a 4.7T NMR spectroscopy system. Using water-NAA chemical shift thermometry, their in vivo experiments recapitulated the linearly changing water-NAA chemical shift difference coefficient of approximately $0.01 \mathrm{ppm} /{ }^{\circ} \mathrm{C}$ across both physiologic and ischemic conditions (slope, $1.00 \pm 0.03$, $r^{2}=0.96$ ), importantly, with little impact by either $\mathrm{pH}$ or protein concentration in physiologically relevant ranges. The authors furthermore reported that even with falling NAA concentrations in ischemic and infarcted tissues, sufficient concentrations remained to allow peak assignment of the NAA resonance. The potential for alternative candidate reference frequencies such as choline or trimethylamines was, nevertheless, tested and confirmed by the authors in subsequent studies, further supporting the feasibility of in vivo brain thermometry in scenarios of falling or undetectable NAA. ${ }^{31,32}$ Of particular interest, the authors reproduced centripetal temperature gradients as measured from directly implanted thermocouples at varying depths, on order of $1^{\circ} \mathrm{C}$ temperature drop from a 1-cm depth to the brain surface.

Later work by Corbett et $\mathrm{al}^{31}$ in healthy human adults again used individual, single-voxel point-resolved spectroscopy spectra (PRESS). By interrogating temperatures in both superficial and deep brain loci, the authors demonstrated, for the first time, that centripetal temperature gradients within the brain itself are amenable to noninvasive detection under clinically practicable conditions. The preceding, however, left the need for noninvasive, real-time detection of fully spatially-resolved temperature gradients unmet, motivating the expansion of existing singlevoxel spectroscopy techniques to multivoxel thermographs in $2 \mathrm{D}$ or $3 \mathrm{D}$. Such multivoxel MR spectroscopic imaging or chemical shift imaging is not, however, without inherent challenges. ${ }^{72,81,82}$ While Ishihara et $\mathrm{al}^{83}$ had reported on the preliminary development of relative cerebral thermal maps using phase-contrast thermography, the dependence of phase-based PRF thermometry on baseline phase mapping (see above) and its potential vulnerability to poorly compensated effects, such as from susceptibility changes, limited its applicability for the reasons detailed above. ${ }^{72,81,84,85}$ Successful extension of singlevoxel spectroscopy to MR spectroscopic imaging-based thermometry was, thereafter, reported by Kuroda et $\mathrm{al}^{81,84}$ in in vitro and in vivo animal studies, though long acquisition times and analytic errors related to chemical shift misregistration and data corruption by lipid contamination are well-recognized challenges to experimentation and clinical use. Acceleration, such as with echo-planar spectroscopic imaging, and more robust signal localization, such as with adiabatic imaging techniques, have been reported with success by multiple investigators, including in our group, with the common goal of robust in vivo thermography (Fig 2). ${ }^{41,59,84,86}$

In vivo multivoxel thermography in human subjects was reported initially by Karaszewski et $\mathrm{al}^{39}$ among a cohort of adult patients with ischemic stroke. The authors attempted to operationalize thermography profiles relative to infarcted and at-risk tissues as defined by diffusion-weighted imaging, reporting generally greater temperatures in possibly abnormal tissues (ie, regions along the immediate periphery of the pathologic DWI lesion). Notwithstanding significant study limitations, including the heterogeneous duration from stroke onset, the absence of perfusion-to-diffusion penumbral estimation, and variable treatment effects, the authors observed that the greatest heating may occur in viably hypoperfused, metabolically active tissues. In contradistinction, somewhat lower temperatures were observed within the more definitively devitalized tissues in the infarction core, in line with past experiments documenting the potential for temperature reduction within the infarcted core of rat brains early after stroke induction using direct thermometry. ${ }^{3}$

Subsequent work by the authors reproduced the findings that the greatest brain temperatures are found in the infarction margins and, importantly, identified unanticipated nonuniformities in temperatures elsewhere throughout the brain; specifically, temperatures in the brain hemisphere contralateral to the stroke were also found to be significantly higher in subjects who were imaged at later times. While such studies are small, observational, and far from conclusive, it can be posited that the convolved effects of perfusion (reduced, absent, or restored following ischemia), metabolic heat production (aerobic and anaerobic), systemic temperatures (physiologic or pyrexic), and variable inflammatory mechanisms (the inflammatory penumbra; mitochondrial uncoupling protein-2) in aggregate determine the temperature profile of infarcted, viably ischemic, and normal/compensated oligemic tissues. These studies confirm the presence of measurable temperature perturbations in ischemic tissues and motivate the further development of operational paradigms of temperature disturbance in stroke.

The preceding human studies of thermometry were inherently limited by the inability to control for the timing of thermometry relative to stroke onset or to track changes longitudinally with sufficient temporal resolution to formalize temperature changes following stroke. Furthermore, the opportunity for local calibration of chemical shift thermometry under clinical scanning conditions has generally been lacking. While several small animal stroke-induction studies attempted to address the former, the generalization of rodent and lower mammal studies to human physiology poses widely cited challenges and may impede translatability in mechanistic and pharmacologic studies. ${ }^{87}$ This issue has motivated further study across stroke neuroscience in gyrencephalic nonhuman primates to facilitate translation.

Our group has undertaken serial studies of noninvasive thermometry in the phylogenetically similar rhesus macaque, 


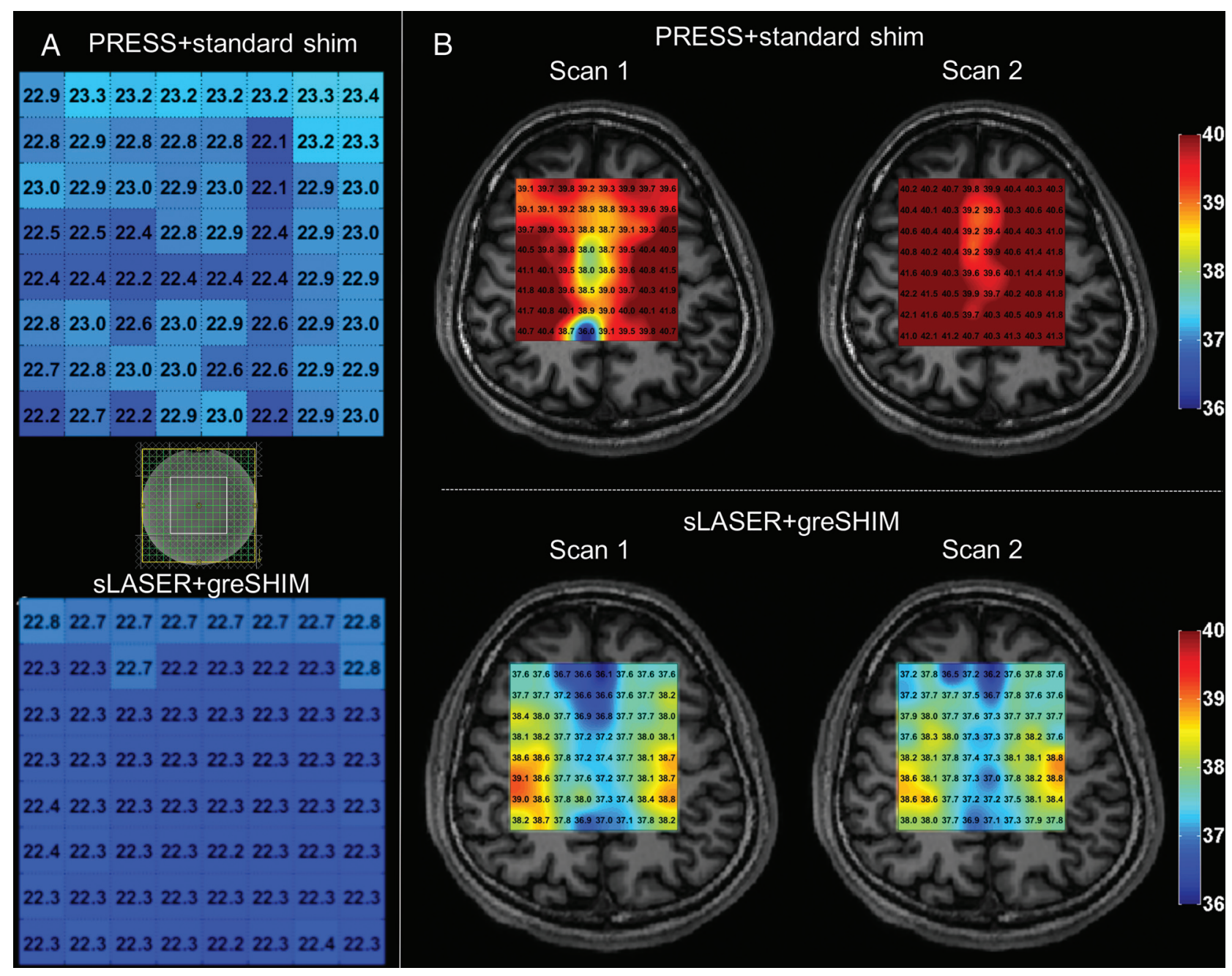

FIG 2. Phantom $(A)$ and human in vivo PRF thermometry in a healthy volunteer $(B)$ using the water-NAA chemical shift, demonstrating the impact of adiabatic (semiLASER) versus conventional volume localization (PRESS) and improvements in the shimming conditions using 3D gradient-echo (greSHIM). Spatially uniform phantom temperatures are noted in A with improvements in SNR, fitted line widths, and test-retest repeatability (not shown) by comparison with conventional point-resolved spectroscopy using sLASER at 3T. Greater test-retest stability obtained 30 minutes apart and the presence of physiologically meaningful temperature gradients are demonstrated to greater advantage in the lower row of $B$ when using sLASER for spatial localization together with greSHIM. Adapted from Dehkharghani et al., ${ }^{8,88}$ with permission from the International Society of Magnetic Resonance in Medicine.

specifically in efforts to bridge this gap. ${ }^{41,76}$ Using robust adiabatic multivoxel chemical shift imaging strategies (sLASER, Siemens Healthineers, Erlangen, Germany) with greater performance against chemical shift misregistration, together with higher order magnetic field shimming, we recently reported on dynamic brain temperature changes following highly-controlled endovascular stroke induction in NHP. ${ }^{41}$ This experimental design permits repeated production of thermographs under physiologic and postischemic conditions without the confounding effects of surgery and ambient heat loss, the constraints of focally implanted temperature probes, or the limitations of unknown disease onset. The preoperative calibration of water-NAA chemical shift thermometry under essentially identical imaging conditions using clinical 3T scanning conditions also facilitates future translation. While the potentially nontrivial effect of anesthesia induction on cerebral blood flow, metabolism, and temperature regulation cannot be overlooked in such models, dynamic imaging immediately following anesthesia induction in control and ischemic experimental sessions fortuitously produces an additional form of physiologic contrast during which temperatures can be measured and compared between conditions.

Across all subjects in our protocol, we observed gradually increasing brain and systemic temperatures, importantly, with steady divergence in brain-to-systemic temperature gradients occurring as the cerebral hyperthermia steadily outpaced even the worsening systemic pyrexia (Fig 3). This dynamic and unpredictable offset stresses the importance of direct brain thermometry in the monitoring of brain injury, owing to the inaccuracies of systemic temperature surrogates in this setting. Furthermore, significant differences in the temperature evolution across time were observed among tissues, independent of worsening systemic hyperthermia, further suggesting the potential for mixed mechanisms of temperature change throughout the brain. 

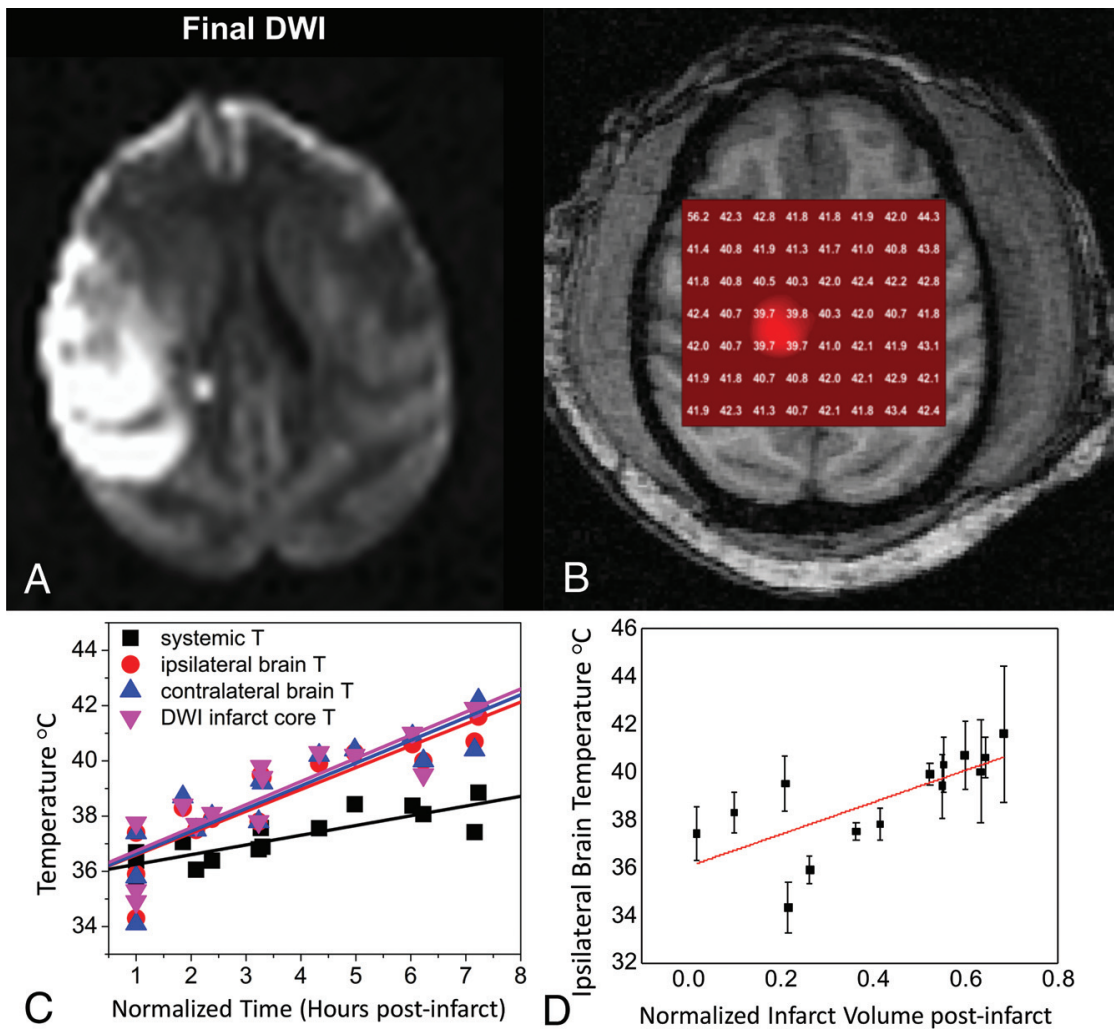

FIG 3. Dynamic MR thermometry following superselective right MCA endovascular stroke induction in an adult rhesus macaque using a low-profile suture embolus. DWI (A) obtained at approximately 7 hours following complete occlusion and contemporaneous 2D axial sLASER chemical shift thermography (see MR Thermometry in Stroke and Cerebrovascular Disease: Acute Ischemic Stroke) following automated and manual shimming (B) demonstrate extensive righthemispheric ischemic injury and generalized cerebral hyperthermia, respectively. Through the course of the experiment, temperatures in both hemispheres were noted to rise, importantly with a differing temporal course and, in both cases, outpacing the influences of the steadily increasing systemic pyrexia $(C)$, measured continuously from an indwelling rectal probe and aggregated over all subjects. The correlation between both normalized infarction size $(C)$ and time from infarction relative to cerebral temperatures was similarly observed across all experimental NHP strokes, and aggregated results are depicted. Adapted from Dehkharghani et al. ${ }^{41}$

(ie, with continued but potentially reduced metabolic activity) tissue beds downstream from chronic stenoocclusive lesions could exhibit a particular propensity for heating through the combination of increased thermogenic oxygen cleavage and reduced perfusion.

Cerebral oximetry and the identification of misery perfusion by MR imaging remain elusive aims and areas of active study by many groups including our own. ${ }^{94-98}$ The unambiguous demonstration of misery perfusion proves challenging without direct MR oximetry, which remains difficult under clinically pragmatic conditions. $^{99,100}$ The characterization of cerebral temperatures could, however, reflect a measurable epiphenomenon of the hemodynamic and metabolic derangements inherent to misery perfusion. In a study of contemporaneous ${ }^{15} \mathrm{O}$-PET and single-voxel pointresolved spectroscopy by Ishigaki et $\mathrm{al},{ }^{101}$ local temperatures and the OEF were estimated in the deep white matter of healthy subjects and patients with unilateral, anterior circulation steno-occlusive disease. As expected, uniformly normal distributions of OEF were measured in healthy subjects, while elevations of $\mathrm{OEF}$ in the diseased territories of patients with steno-occlusive disease were observed as compensations for reduced blood flow. The authors also confirmed the hypothesized inter-

Chronic Cerebrovascular Ischemia. Hemodynamic and thermoregulatory theory predict a strong dependency of brain temperature on blood flow, which has largely been confirmed during experimentation in low-flow states such as ischemic stroke as described above. The theoretic, converse cooling effects of hemodynamic augmentation are, however, more difficult to test experimentally. A brief review of the dynamic autoregulatory process underlying hemodynamic failure is worthwhile at this stage. The response of the cerebrovascular system to falling perfusion pressures was expounded in initial work by Powers and further by Derdeyn et al. ${ }^{89,90}$ using ${ }^{15} \mathrm{O}-\mathrm{PET} .{ }^{89-93}$ A sequential, quasi-stepwise response to incremental hemodynamic failure is commonly encountered, culminating in the up-regulation of the oxygen extraction fraction (OEF) from the heme moiety of hemoglobin to sustain the cerebral metabolic rate of oxygen when falling perfusion pressures outstrip the cerebrovascular reserve. This tenuous state of so-called misery perfusion would, on the basis of cerebral thermoregulatory theory, seem conducive to heating. Specifically, one would anticipate that viable actions between interhemispheric temperature offset and OEF. While the findings are compelling as potential evidence for brain temperatures as an imaging biomarker in chronic ischemia, the comprehensive characterization of tissue thermal signatures in hemodynamic failure would require acquisition of thermographs to assess the spatiotemporal relationship between perfusion and temperature.

To this end, we recently reported on cerebral multivoxel thermography in patients with chronic, unilateral anterior circulation steno-occlusive disease, leveraging the hemodynamic contrast of acetazolamide augmentation. ${ }^{80}$ We hypothesized the presence of a detectable modulation of cerebral temperatures by cerebrovascular augmentation, which we have coined the "brain thermal response" (BTR, Fig 4), which we compared with both $\mathrm{CBF}$ (using multidelay arterial spin-labeling) and blood oxygen level-dependent (BOLD) augmentation. In accordance with aforementioned observations by Ishigaki et al, ${ }^{101}$ while highly significant interactions were observed between augmentation and temperature, the relationship appears to be unsurprisingly 


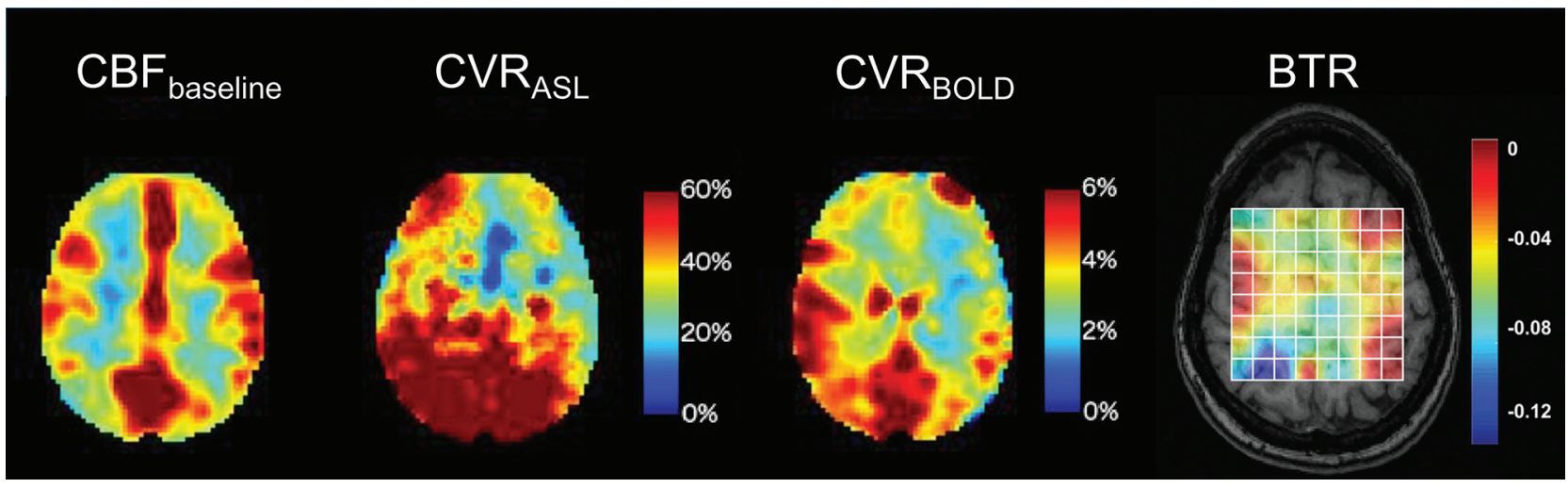

FIG 4. Cerebrovascular reserve (CVR) percentage augmentation maps calculated with BOLD and arterial spin-labeling (ASL), as well as a BTR map overlaid on a T1-weighted anatomic image. Images are all from the same subject (a 32-year-old woman with unilateral left MCA stenosis and multiple TIAs). The white grid overlay represents the MR thermometry VOI derived from multivoxel spectroscopy analysis using the water-NAA chemical shift difference. Images are displayed in the radiologic convention. Impaired cerebrovascular reserve in the left hemisphere is present in both BOLD and ASL, with a greater severity of impairment in arterial spin-labeling, likely related to tag decay and residual delay sensitivity despite the use of 10 separate, in-line postlabel delays of varying duration. The BTR map demonstrates an asymmetric thermal response, with less brain cooling following vasodilatory stimulus in the diseased left hemisphere, indicated by reduced (ie, less negative) BTR values and corresponding primarily to the areas of greatest impairment in the anterior and posterior MCA borderzone territories. Maximal (most negative) BTRs are noted in the regions spatially concordant with the greatest hemodynamic augmentation (blue regions) in the right parietal lobe. Adapted from Fleischer et al. $^{80}$
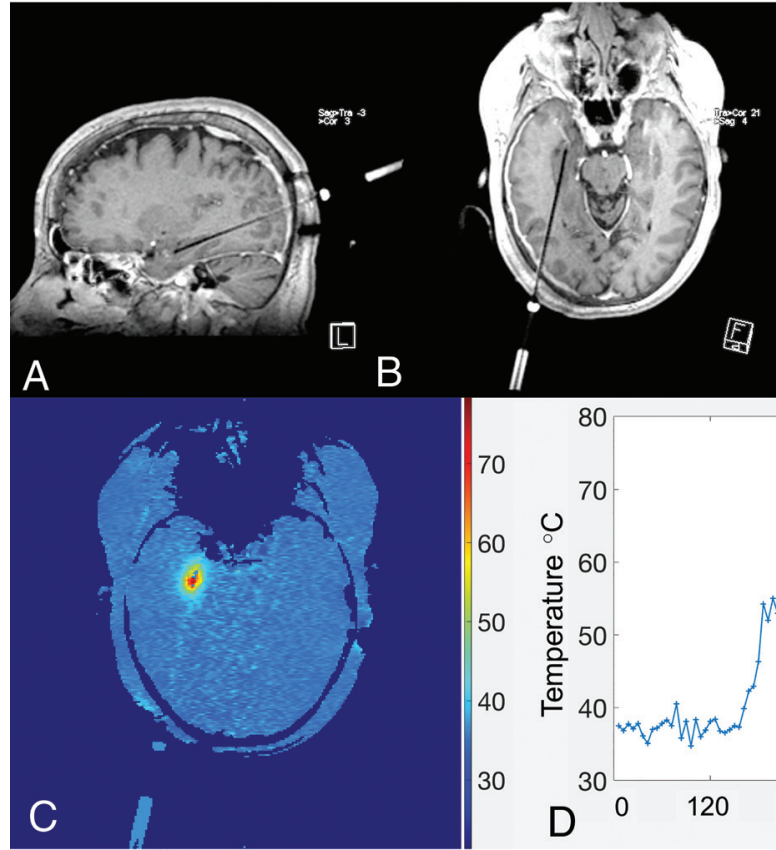

因
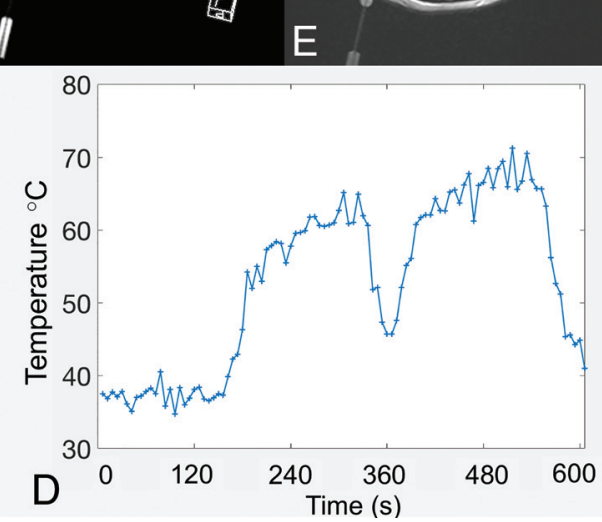

FIG 5. Real-time temperature mapping using phase-based PRF thermometry during stereotactic laser amygdalohippocampectomy for mesial temporal lobe epilepsy. Multiplanar spoiled gradient T1-weighted images obtained with intravenous gadolinium ( $A$ and $B$ ) demonstrate a stereotactically introduced, right-posterior-approach ablative probe, terminating within the right hippocampal formation. A parametric thermal map with inset scale and a temperature-time course graph ( $C$ and $D$, respectively) demonstrate that the estimated, relative temperature change from baseline following ablation exceeded $30^{\circ} \mathrm{C}$. Contrast-enhanced T2-FLAIR axial image $(E)$ through the treatment bed confirms the final zone of ablative injury.

complex and nonlinear. In particular, BOLD augmentation reflects a convolved effect of flow and volume and also, critically, of blood oxygenation/oxygen extraction. This latter effect, which may be variably up-regulated at baseline, depending on the metabolic need and also on vasoreactivity and disease chronicity, is difficult to measure directly. However, in concert, these variables likely determine the direction of the baseline arterial bloodto-brain temperature offset and, therefore, the magnitude and direction of the BTR. While further investigation into the diagnostic and prognostic merits of BTR are underway, we anticipate that the overarching mechanisms are governed by already well-recognized principles of cerebral hemodynamic control and thermoregulation and reflect a tendency for tissue heating arising from impaired perfusion and up-regulated OEF. $^{80,101}$

An interesting potential implication of such thermal disturbance in cerebrovascular disease was described recently by Murakami et al, ${ }^{103}$ who explored the potential for preoperative hyperthermia as a predictor of post-carotid endarterectomy hyperperfusion syndrome. A strong and highly significant correlation was observed between baseline temperature elevation and potentially dangerous post-carotid endarterectomy blood flow augmentation $(r=0.763$, $P<.001)$. Similarly, our experience with the BTR demonstrated a significant negative relationship between baseline temperatures and cerebrovascular reserve capacity, in line with past reports of impaired cerebrovascular reserve capacity as a strong predictor of hyperperfusion syndrome. ${ }^{104}$ 
MR Thermometry in Thermal Therapy. MR thermometry has found broad applications in the real-time monitoring of thermal therapies, and despite obvious differences from the preceding sections, for completeness, we introduce the reader to this emergent application of cerebral thermometry.

The coagulative response of thermally injured tissue is a function of both maximal temperature and the duration over which it is sustained beyond the ablative threshold. In such applications, MRT can be used to ensure that temperatures in target regions are sustained at prespecified levels to achieve coagulation and fatal thermal dose. In combination with sophisticated dose and thermal models, the use of real-time monitoring affords greater safety in such procedures by ensuring that ablative doses not exceed cavitation thresholds and by confirming that temperatures in vulnerable and eloquent nearby regions remain below injurious ranges (Fig 5). The scale of temperature change in these applications is on the order of tens of degrees Celsius and, hence, much larger than that described either in basal cerebral temperature gradients or occurring in the pathophysiologic states discussed elsewhere in this review. During thermal therapy, the baseline cerebral temperature gradient can therefore be neglected and the temperatures assumed to be spatially homogeneous and equal to the systemic temperature. By freeing the methodology from the demands for absolute, baseline temperature estimation, many alternative approaches to thermometry can be used in such applications beyond those discussed for the study of cerebral thermoregulation described herein. ${ }^{71}$

\section{CONCLUSIONS}

This review introduces the reader to fundamental aspects of cerebral and systemic thermoregulation, emphasizing the importance of tight cerebral thermoregulation in homeotherms and specifically the vulnerability of the ischemic neurovascular unit to the effects of hyperthermia. Temperature represents a powerful biomarker of brain function and a potentially valuable target for interrogation through noninvasive means as permitted by emerging cerebral MR thermometry techniques. We believe that cerebral temperatures are, therefore, well-suited for diagnostic and prognostic purposes and mechanistic study and hope to see them find their way deeper into the scientific agenda of the neuroimaging community.

Disclosures: Seena Dehkharghani-RELATED: Grant: Foundation of the ASNR, Emory University Research Council, Comments: Scholar Award in Neuroradiology Research in the name of the lead author in successive years, Emory University Research Council Grant to the lead author*; Support for Travel to Meetings for the Study or Other Purposes: Foundation of the ASNR*; UNRELATED: Travel/Accommodations/Meeting Expenses Unrelated to Activities Listed: ISchemaView, Comments: travel costs. Deqiang Qiu-UNRELATED: Grants/ Grants Pending: Siemens. * Money paid to the institution.

\section{REFERENCES}

1. Busto R, Dietrich WD, Globus MY, et al. The importance of brain temperature in cerebral ischemic injury. Stroke 1989;20:1113-14 CrossRef Medline

2. Busto R, Dietrich WD, Globus MY, et al. Small differences in intraischemic brain temperature critically determine the extent of ischemic neuronal injury. J Blood Flow Metab 1987;7:729-38 CrossRef Medline
3. Minamisawa H, Mellergard P, Smith ML, et al. Preservation of brain temperature during ischemia in rats. Stroke 1990;21:758-64 CrossRef CrossRef Medline

4. Minamisawa $\mathrm{H}$, Nordstrom $\mathrm{CH}$, Smith $\mathrm{ML}$, et al. The influence of mild body and brain hypothermia on ischemic brain damage. $J$ Cereb Blood Flow Metab 1990;10:365-74 CrossRef Medline

5. Wass CT, Lanier WL, Hofer RE, et al. Temperature changes of > or = 1 degree $\mathrm{C}$ alter functional neurologic outcome and histopathology in a canine model of complete cerebral ischemia. Anesthesiology 1995;83:325-35 CrossRef Medline

6. Axelrod YK, Diringer MN. Temperature management in acute neurologic disorders. Neurol Clin 2008;26:585-603, xi CrossRef Medline

7. Saad H, Aladawy M. Temperature management in cardiac surgery. Glob Cardiol Sci Pract 2013;2013:44-62 CrossRef Medline

8. Baker MA. Brain cooling in endotherms in heat and exercise. Annu Rev Physiol 1982;44:85-96 CrossRef Medline

9. Zhu M, Ackerman JJ, Sukstanskii AL, et al. How the body controls brain temperature: the temperature shielding effect of cerebral blood flow. J Appl Physiol 2006;101:1481-88 CrossRef Medline

10. Zhu M, Ackerman JJ, Yablonskiy DA. Body and brain temperature coupling: the critical role of cerebral blood flow. J Comp Physiol B 2009;179:701-10 CrossRef Medline

11. Falk D. Brain evolution in homo: the "radiator" theory. Behav Brain Sci 1990;13:333-44 CrossRef

12. Baker MA, Hayward JN. Intracranial heat exchange and regulation of brain temperature in sheep. Life SCI 1968;7:349-57 CrossRef Medline

13. Baker MA. A brain-cooling system in mammals. Sci Am 1979; 240:130-39 CrossRef Medline

14. Cabanac M, Caputa M. Natural selective cooling of the human brain: evidence of its occurrence and magnitude. J Physiol 1979; 286:255-64 CrossRef Medline

15. Hayward JN, Baker MA. Role of cerebral arterial blood in the regulation of brain temperature in the monkey. Am J Physiol 1968; 215:389-403 CrossRef Medline

16. Cabanac M. Selective brain cooling in humans: "fancy" or fact? FASEB J 1993;7:1143-46; discussion 1146-47 Medline

17. Caputa M. Selective brain cooling: a multiple regulatory mechanism. J Therm Biol 2004;29:691-702 CrossRef

18. Falk D. Brain evolution in homo: the radiator theory. Behavioral and Brain Sciences 1990;13:333-34 CrossRef

19. Falk D. Evolution of the primate brain. In: Handbook of Paleoanthropology. Berlin: Springer-Verlag; 2007:1133-62

20. Kuhnen G, Jessen C. Thermal signals in control of selective brain cooling. Am J Physiol 1994;267:R355-59 CrossRef Medline

21. Yablonskiy DA, Ackerman JJ, Raichle ME. Coupling between changes in human brain temperature and oxidative metabolism during prolonged visual stimulation. Proc Natl Acad Sci U S A 2000;97:7603-08 CrossRef Medline

22. Zhu L, Diao C. Theoretical simulation of temperature distribution in the brain during mild hypothermia treatment for brain injury. Med Biol Eng Comput 2001;39:681-87 CrossRef Medline

23. Stone JG, Young WL, Smith CR, et al. Do standard monitoring sites reflect true brain temperature when profound hypothermia is rapidly induced and reversed? Anesthesiology 1995;82:344-51 CrossRef Medline

24. Simon E. Tympanic temperature is not suited to indicate selective brain cooling in humans: a re-evaluation of the thermophysiological basics. Eur J Appl Physiol 2007;101:19-30 CrossRef Medline

25. Baker MA, Stocking RA, Meehan JP. Thermal relationship between tympanic membrane and hypothalamus in conscious cat and monkey. J Appl Physiol 1972;32:739-42 CrossRef Medline

26. McCaffrey TV, McCook RD, Wurster RD. Effect of head skin temperature on tympanic and oral temperature in man. J Appl Physiol 1975;39:114-18 CrossRef Medline 
27. Cady EB, D'Souza PC, Penrice J, et al. The estimation of local brain temperature by in vivo $1 \mathrm{H}$ magnetic resonance spectroscopy. Magn Reson Med 1995;33:862-67 CrossRef Medline

28. Childs C, Hiltunen Y, Vidyasagar R, et al. Determination of regional brain temperature using proton magnetic resonance spectroscopy to assess brain-body temperature differences in healthy human subjects. Magn Reson Med 2007;57:59-66 CrossRef Medline

29. Corbett RJ, Laptook AR, Tollefsbol G, et al. Validation of a noninvasive method to measure brain temperature in vivo using $1 \mathrm{H}$ NMR spectroscopy. J Neurochem 1995;64:1224-30 CrossRef Medline

30. Schwab S, Spranger M, Aschoff A, et al. Brain temperature monitoring and modulation in patients with severe MCA infarction. Neurology 1997;48:762-67 CrossRef Medline

31. Corbett R, Laptook A, Weatherall P. Noninvasive measurements of human brain temperature using volume-localized proton magnetic resonance spectroscopy. J Cereb Blood Flow Metab 1997;17: 363-69 CrossRef Medline

32. Corbett RJ, Purdy PD, Laptook AR, et al. Noninvasive measurement of brain temperature after stroke. AJNR Am J Neuroradiol 1999;20:1851-57 Medline

33. Verlooy J, Heytens L, Veeckmans G, et al. Intracerebral temperature monitoring in severely head injured patients. Acta Neurochir (Wien) 1995;134:76-78 CrossRef Medline

34. Sun Z, Zhang J, Chen Y, et al. Differential temporal evolution patterns in brain temperature in different ischemic tissues in a monkey model of middle cerebral artery occlusion. J Biomed Biotechnol 2012;2012:980961 CrossRef Medline

35. Sukstanskii AL, Yablonskiy DA. Theoretical limits on brain cooling by external head cooling devices. Eur J Appl Physiol 2007;101: 41-49 CrossRef Medline

36. Soukup J, Rieger A, Holz C, et al. Temperature gradient between brain tissue and arterial blood mirrors the flow-metabolism relationship in uninjured brain: an experimental study. Acta Anaesthesiol Scand 2007;51:872-79 CrossRef Medline

37. Otawara Y, Ogasawara K, Kubo Y, et al. Brain and systemic temperature in patients with severe subarachnoid hemorrhage. Surg Neurol 2003;60:159-64; discussion 164 CrossRef Medline

38. Mellergard $\mathrm{P}$. Changes in human intracerebral temperature in response to different methods of brain cooling. Neurosurgery 1992;31:671-77; discussion 677 Medline

39. Karaszewski B, Wardlaw JM, Marshall I, et al. Measurement of brain temperature with magnetic resonance spectroscopy in acute ischemic stroke. Ann Neurol 2006;60:438-46 CrossRef Medline

40. Kalmbach AS, Waters J. Brain surface temperature under a craniotomy. J Neurophysiol 2012;108:3138-46 CrossRef Medline

41. Dehkharghani S, Fleischer CC, Qiu D, et al. Cerebral temperature dysregulation: MR thermographic monitoring in a nonhuman primate study of acute ischemic stroke. AJNR Am J Neuroradiol 2017;38:712-20 CrossRef Medline

42. Pennes HH. Analysis of tissue and arterial blood temperatures in the resting human forearm. J Appl Physiol 1948;1:93-22 CrossRef Medline

43. Nelson DA, Nunneley SA. Brain temperature and limits on transcranial cooling in humans: quantitative modeling results. Eur J Appl Physiol Occup Physiol 1998;78:353-59 CrossRef Medline

44. Sukstanskii AL, Yablonskiy DA. An analytical model of temperature regulation in human head. J Therm Biol 2004;29:583-87 CrossRef

45. Sukstanskii AL, Yablonskiy DA. Theoretical model of temperature regulation in the brain during changes in functional activity. Proc Natl Acad Sci USA 2006;103:12144-49 CrossRef Medline

46. Wissler EH. Pennes' 1948 paper revisited. J Appl Physiol 1998;85: 35-41 CrossRef Medline

47. Collins CM, Smith MB, Turner R. Model of local temperature changes in brain upon functional activation. J Appl Physiol 2004; 97:2051-55 CrossRef Medline

48. Minamisawa H, Smith ML, Siesjo BK. The effect of mild hyperthermia and hypothermia on brain damage following 5,10 , and
15 minutes of forebrain ischemia. Ann Neurol 1990;28:26-33 CrossRef Medline

49. Hosler RM. The emergency treatment of cardiac arrest. J Int Coll Surg 1953;19:336-40 Medline

50. Wolfe KB. Effect of hypothermia on cerebral damage resulting from cardiac arrest. Am J Cardiol 1960;6:809-12 CrossRef Medline

51. Donnelly CJ, Frobese AS, Stone HH. The effect of lowered body temperature on the cerebral hemodynamics and metabolism of man. Surg Gynecol Obstet 1956;103:313-7 Medline

52. Ginsberg MD, Sternau LL, Globus MY, et al. Therapeutic modulation of brain temperature: relevance to ischemic brain injury. Cerebrovasc Brain Metab Rev 1992;4:189-25 Medline

53. Dehkharghani S, Bowen M, Haussen DC, et al. Body temperature modulates infarction growth following endovascular reperfusion. AJNR Am J Neuroradiol 2017;38:46-51 CrossRef Medline

54. Dietrich WD, Busto R, Halley M, et al. The importance of brain temperature in alterations of the blood-brain barrier following cerebral ischemia. J Neuropathol Exp Neurol 1990;49:486-97 CrossRef Medline

55. Dietrich WD, Busto R, Valdes I, et al. Effects of normothermic versus mild hyperthermic forebrain ischemia in rats. Stroke 1990;21 1318-25 CrossRef Medline

56. Ginsberg MD, Busto R. Combating hyperthermia in acute stroke a significant clinical concern. Stroke 1998;29:529-34 CrossRef Medline

57. Karaszewski B, Thomas RG, Dennis MS, et al. Temporal profile of body temperature in acute ischemic stroke: relation to stroke severity and outcome. BMC Neurol 2012;12:123 CrossRef Medline

58. Karaszewski B, Wardlaw JM, Marshall I, et al. Early brain temperature elevation and anaerobic metabolism in human acute ischaemic stroke. Brain 2009;132:955-64 CrossRef Medline

59. Maudsley AA, Goryawala MZ, Sheriff S. Effects of tissue susceptibility on brain temperature mapping. Neuroimage 2017;146:10931101 CrossRef Medline

60. Wrotek SE, Kozak WE, Hess DC, et al. Treatment of fever after stroke: conflicting evidence. Pharmacotherapy 2011;31:1085-91 CrossRef Medline

61. Gauberti M, De Lizarrondo SM, Vivien D. The “inflammatory penumbra" in ischemic stroke: from clinical data to experimental evidence. Eur Stroke J 2016;1:20-27 CrossRef Medline

62. Gauberti M, Montagne A, Marcos-Contreras OA, et al. Ultra-sensitive molecular MRI of vascular cell adhesion molecule- 1 reveals a dynamic inflammatory penumbra after strokes. Stroke 2013;44 1988-96 CrossRef Medline

63. Han HS, Karabiyikoglu M, Kelly S, et al. Mild hypothermia inhibits nuclear factor-kappa B translocation in experimental stroke. J Cereb Blood Flow Metab 2003;23:589-98 CrossRef Medline

64. Inamasu J, Suga $S$, Sato $S$, et al. Postischemic hypothermia attenuates apoptotic cell death in transient focal ischemia in rats. Acta Neurochir Suppl 2000;76:525-27 CrossRef Medline

65. Ohmura A, Nakajima W, Ishida A, et al. Prolonged hypothermia protects neonatal rat brain against hypoxic-ischemia by reducing both apoptosis and necrosis. Brain Dev 2005;27:517-26 CrossRe Medline

66. Wang GJ, Deng HY, Maier CM, et al. Mild hypothermia reduces ICAM-1 expression, neutrophil infiltration and microglia/monocyte accumulation following experimental stroke. Neuroscience 2002;114:1081-90 CrossRef Medline

67. Haussen DC, Nogueira RG, Elhammady MS, et al. Infarct growth despite full reperfusion in endovascular therapy for acute ischemic stroke. J Neurointerv Surg 2016;8:117-21 CrossRef Medline

68. Diringer MN, Reaven NL, Funk SE, et al. Elevated body temperature independently contributes to increased length of stay in neurologic intensive care unit patients. Crit Care Med 2004; 32:1489-95 CrossRef Medline

69. Kilpatrick MM, Lowry DW, Firlik AD, et al. Hyperthermia in the neurosurgical intensive care unit. Neurosurgery 2000;47:850-55; discussion 855-56 CrossRef Medline 
70. Parker DL, Smith V, Sheldon P, et al. Temperature distribution measurements in two-dimensional NMR imaging. Med Phys 1983; 10:321-25 CrossRef Medline

71. Rieke V, Butts Pauly K. MR thermometry. J Magn Reson Imaging 2008;27:376-90 CrossRef Medline

72. Kuroda K. Non-invasive MR thermography using the water proton chemical shift. Int J Hyperthermia 2005;21:547-60 CrossRef Medline

73. Coman D, Trubel HK, Rycyna RE, et al. Brain temperature and pH measured by (1) $\mathrm{H}$ chemical shift imaging of a thulium agent. NMR Biomed 2009;22:229-39 CrossRef Medline

74. Hekmatyar SK, Kerkhoff RM, Pakin SK, et al. Noninvasive thermometry using hyperfine-shifted MR signals from paramagnetic lanthanide complexes. Int J Hyperthermia 2005;21:561-74 CrossRef Medline

75. Lindner LH, Reinl HM, Schlemmer M, et al. Paramagnetic thermosensitive liposomes for MR-thermometry. Int J Hyperthermia 2005;21:575-88 CrossRef Medline

76. Dehkharghani S, Mao H, Howell L, et al. Proton resonance frequency chemical shift thermometry: experimental design and validation toward high-resolution noninvasive temperature monitoring and in vivo experience in a nonhuman primate model of acute ischemic stroke. AJNR Am J Neuroradiol 2015;36:1128-35 CrossRef Medline

77. Hindman J. Proton resonance shift of water in the gas and liquid states. The Journal of Chemical Physics 1966;44:4582-92 CrossRef

78. Zou C, Tie C, Pan M, et al. Referenceless MR thermometry-a comparison of five methods. Phys Med Biol 2017;62:1-16 CrossRef Medline

79. Cady EB, Penrice J, Robertson NJ. Improved reproducibility of MRS regional brain thermometry by "amplitude-weighted combination.” NMR Biomed 2011;24:865-72 CrossRef Medline

80. Fleischer CC, Wu J, Qiu D, et al. The brain thermal response as a potential neuroimaging biomarker of cerebrovascular impairment. AJNR Am J Neuroradiol 2017;38:2044-51 CrossRef Medline

81. Kuroda K, Suzuki Y, Ishihara Y, et al. Temperature mapping using water proton chemical shift obtained with 3D-MRSI: feasibility in vivo. Magn Reson Med 1996;35:20-29 CrossRef Medline

82. Kuroda $\mathrm{K}$, Oshio $\mathrm{K}$, Chung $\mathrm{AH}$, et al. Temperature mapping using the water proton chemical shift: a chemical shift selective phase mapping method. Magn Reson Med 1997;38:845-51 CrossRef Medline

83. Ishihara $\mathrm{Y}$, Calderon $\mathrm{A}$, Watanabe $\mathrm{H}$, et al. A precise and fast temperature mapping using water proton chemical shift. Magn Reson Med 1995;34:814-23 CrossRef Medline

84. Kuroda K, Mulkern RV, Oshio $\mathrm{K}$, et al. Temperature mapping using the water proton chemical shift: self-referenced method with echo-planar spectroscopic imaging. Magn Reson Med 2000; 43:220-25 CrossRef Medline

85. De Poorter J. Noninvasive MRI thermometry with the proton resonance frequency method: study of susceptibility effects. Magn Reson Med 1995;34:359-67 CrossRef Medline

86. Dehkharghani S, Wei L, Mao H, et al. Multivoxel proton spectroscopy for non-invasive MR thermometry: phantom comparison of PRESS and semiLASER-localized chemical shift imaging for temperature monitoring. In: Proceedings of the Joint Meeting of the International Society of Magnetic Resonance in Medicine and the European Society of Magnetic Resonance in Medicine and Biology, Milan, Italy. May 10-16, 2014; 2828

87. Cook DJ, Tymianski M. Nonhuman primate models of stroke for translational neuroprotection research. Neurotherapeutics 2012;9: 371-79 CrossRef Medline

88. Dehkharghan S, Fleischer CC, Qiu D, et al. Non-Invasive Brain MR Thermometry in a Nonhuman Primate Model of Acute Ischemic Stroke, ISMRM Annual Meeting 2017; Honolulu, HI
89. Derdeyn CP, Videen TO, Fritsch SM, et al. Compensatory mechanisms for chronic cerebral hypoperfusion in patients with carotid occlusion. Stroke 1999;30:1019-24 CrossRef Medline

90. Derdeyn CP, Videen TO, Yundt KD, et al. Variability of cerebral blood volume and oxygen extraction: stages of cerebral haemodynamic impairment revisited. Brain 2002;125:595-607 CrossRef Medline

91. Powers WJ. Cerebral hemodynamics in ischemic cerebrovascular disease. Ann Neurol 1991;29:231-40 CrossRef Medline

92. Powers WJ. Stroke: misery perfusion in cerebrovascular diseaseis it important? Nat Rev Neurol 2012;8:479-80 CrossRef Medline

93. Powers WJ, Press GA, Grubb RL Jr, et al. The effect of hemodynamically significant carotid artery disease on the hemodynamic status of the cerebral circulation. Ann Intern Med 1987;106:27-34 CrossRef Medline

94. Yablonskiy DA, Sukstanskii AL, He X. Blood oxygenation level-dependent (BOLD)-based techniques for the quantification of brain hemodynamic and metabolic properties: theoretical models and experimental approaches. NMR Biomed 2013;26:963-86 CrossRef Medline

95. Wu J, Dehkharghani S, Nahab F, et al. Acetazolamide-augmented dynamic BOLD (aczBOLD) imaging for assessing cerebrovascular reactivity in chronic steno-occlusive disease of the anterior circulation: an initial experience. Neuroimage Clin 2017;13:116-22 CrossRef Medline

96. Wu J, Dehkharghani S, Nahab F, et al. The effects of acetazolamide on the evaluation of cerebral hemodynamics and functional connectivity using blood oxygen level-dependent MR imaging in patients with chronic steno-occlusive disease of the anterior circulation. AJNR Am J Neuroradiol 2017;38:139-45 CrossRef Medline

97. Leatherday C, Dehkharghani S, Nahab F, et al. Cerebral MR oximetry during acetazolamide augmentation: beyond cerebrovascular reactivity in hemodynamic failure. J Magn Reson Imaging 2019; 50:175-82 CrossRef Medline

98. Christen T, Bolar DS, Zaharchuk G. Imaging brain oxygenation with MRI using blood oxygenation approaches: methods, validation, and clinical applications. AJNR Am J Neuroradiol 2013;34: 1113-23 CrossRef Medline

99. Atkinson IC, Thulborn KR. Feasibility of mapping the tissue mass corrected bioscale of cerebral metabolic rate of oxygen consumption using 17-oxygen and 23-sodium MR imaging in a human brain at 9.4 T. Neuroimage 2010;51:723-33 CrossRef Medline

100. Lakshmanan K, Dehkharghani S, Madelin G, et al. A dual-tuned (17) $\mathrm{O} /(1) \mathrm{H}$ head array for direct brain oximetry at 3 Tesla. Magn Reson Med 2020;83:1512-18 CrossRef Medline

101. Ishigaki D, Ogasawara $\mathrm{K}$, Yoshioka $\mathrm{Y}$, et al. Brain temperature measured using proton MR spectroscopy detects cerebral hemodynamic impairment in patients with unilateral chronic major cerebral artery steno-occlusive disease: comparison with positron emission tomography. Stroke 2009;40:3012-16 CrossRef Medline

102. Nanba T, Nishimoto H, Yoshioka $Y$, et al. Apparent brain temperature imaging with multi-voxel proton magnetic resonance spectroscopy compared with cerebral blood flow and metabolism imaging on positron emission tomography in patients with unilateral chronic major cerebral artery steno-occlusive disease. Neuroradiology 2017;59:923-35 CrossRef Medline

103. Murakami T, Ogasawara K, Yoshioka Y, et al. Brain temperature measured by using proton MR spectroscopy predicts cerebral hyperperfusion after carotid endarterectomy. Radiology 2010;256: 924-31 CrossRef Medline

104. Buczek J, Karliński M, Kobayashi A, et al. Hyperperfusion syndrome after carotid endarterectomy and carotid stenting. Cerebrovasc Dis 2013;35:531-37 CrossRef Medline 